\title{
INFLUENCIA DOS ÓLEOS VEGETAIS E DA CERA DE ABELHA SOBRE A VULCANIZAÇÃO DO COPOLÍMERO DE ESTIRENO-BUTADIENO (SBR)
}

\section{INFLUENCE OF THE VEGETABLE OILS AND BEESWAX UPON STYRENE-BUTADIENE COPOLYMER (SBR) VULCANIZATION}

\author{
H. M. da COSTA ${ }^{1,2}$, V. D. RAMOS ${ }^{2}$ e A. S. SIRQUEIRA ${ }^{3}$ \\ ${ }^{1}$ Universidade do Estado do Rio de Janeiro, Departamento de Materiais, Brasil \\ ${ }^{2}$ Universidade Estácio de Sá, Departamento de Engenharia, Brasil \\ ${ }^{3}$ Fundação Centro Universitário Estadual da Zona Oeste, Departamento de Materiais, Brasil \\ E-mail: moreirahelson@gmail.com
}

\author{
article info \\ Article history: \\ Received 2017-05-12 \\ Accepted 2017-07-13 \\ Available online 2017-11-20
}

PALAVRAS-CHAVE: Vulcanização; Óleos vegetais; Cinética; Borracha de estireno-butadieno.

KEYWORDS: Vulcanization; Vegetable oils; Kinetics; Styrene-butadiene rubber

RESUMO: Nesta investigação, o ácido esteárico presente em composições da borracha de estireno-butadieno (SBR) foi substituído por óleos vegetais (amendoim, coco ou linhaça) ou cera de abelha, a fim de se avaliar o potencial ativador de tais substâncias. Após o processamento em misturador de cilindros, os diferentes parâmetros reológicos $\left(S_{\ell}^{\prime}, S_{h}{ }_{h}, t_{s l}\right.$ e t90) e os parâmetros cinéticos $\left(k, n, E_{a}\right)$ foram obtidos através de um $R P A$ 2000 Rubber Process Analyzer. Os dados experimentais, após tratamento estatístico pela metodologia ANOVA, revelaram que a cera de abelha não apresenta desempenho satisfatório para o sistema de vulcanização escolhido, enquanto os óleos vegetais têm sua ação influenciada pela porcentagem e tipo de ácidos graxos presentes em sua composição química.

\begin{abstract}
In this investigation, stearic acid present in the styrene-butadiene rubber (SBR) compositions was replaced by vegetable oils (peanut, coconut or linseed) or beeswax in order to evaluate the activating potential of these substances. After processing in two-roll mixer, the different rheological parameters $\left(S_{\ell}{ }_{\ell}, S_{h}{ }_{h}\right.$, $t_{s 1}$ e t90) and kinetic parameters $\left(k, n, E_{a}\right)$ were obtained from RPA 2000 Rubber Process Analyzer. Experimental data, after statistical treatment by ANOVA methodology, showed that beeswax does not present satisfactory performance for the vulcanization system chosen, while vegetable oils have action influenced by content and type of fatty acids present in the chemical composition.
\end{abstract}

\section{INTRODUÇÃO}

A vulcanização é a tecnologia chave de uma vasta indústria que produz artefatos variados em borracha. Porém, a preparação de um produto comercial específico através da vulcanização de um elastômero requer a seleção de matérias-primas básicas e a obtenção de uma formulação ou composição. A arte e a ciência da seleção de vários ingredientes para uma formulação, assim como a definição da quantidade de cada ingrediente, permite o 
processamento satisfatório, o alcance das propriedades desejadas e o preço final competitivo - os três P's - de um artefato (STEPHENS, 1999; DICK, 2001).

Há dezenas de milhares de formulações diferentes que são usadas na indústria da borracha. Essa diversidade existe porque há várias maneiras de se atingir um conjunto de propriedades requeridas para um artefato. Por exemplo, através de diferentes borrachas e misturas de borrachas, diferentes sistemas de cura e diferentes combinações de cargas e óleos. Uma vez que o desenvolvimento de uma composição que atenda aos três $P$ 's pode custar milhares de dólares, as companhias tendem a manter sob sigilo suas formulações (DICK, 2001).

Industrialmente, admitem-se vários aditivos na composição da borracha, os quais são adicionados em partes em relação ao total de elastômero utilizado. Borrachas com aditivos em até 30 partes são chamados de gomas puras; relativamente macias, maleáveis e esticáveis, são muito úteis na confecção de tubos e luvas, mas, para outros usos, faz-se necessária a utilização de cargas de reforço que melhoram as propriedades mecânicas, como a resistência à tração, dureza, resistência ao rasgo e à abrasão (MARINHO, 2005). Os aditivos podem ser subdivididos de acordo com suas estruturas químicas ou de acordo com suas aplicações. Diversas classes de substâncias podem ter mais de uma aplicação. A ASTM D5899, publicada em 1996, por exemplo, dá 18 diferentes classificações funcionais para os ingredientes de uma composição de borracha (DICK, 2001; MONEYPENNY et al., 2004; MARINHO, 2005).

Os elastômeros de uso geral - borracha natural (NR), poli-isopreno (IR), polibutadieno (BR), e o copolímero estireno-butadieno (SBR) - são os "burros de carga" (work horses) da indústria de pneus e de produtos mecânicos a partir de borrachas. Essas borrachas exibem boas propriedades físicas, processabilidade, compatibilidade e, geralmente, são de baixo custo em função do volume de produção. A composição, processamento e cura são muito similares para todas as três borrachas, sendo o ácido esteárico o ácido graxo mais largamente empregado nos sistemas de vulcanização (DICK, 2001).

Os lipídeos mais simples construídos a partir de ácidos graxos são os triacilgliceróis, também chamados de triglicerídeos, gorduras ou gorduras neutras. Os triacilgliceróis são compostos por três ácidos graxos, cada um em ligação éster com uma molécula de glicerol. Aqueles que contêm o mesmo tipo de ácido graxo em todas as três posições são chamados de triacilgliceróis simples, e sua nomenclatura é derivada do ácido graxo que contêm. A maioria dos triacilgliceróis de ocorrência natural é mista, pois contém dois ou três ácidos graxos diferentes. Como as hidroxilas polares do glicerol e os carboxilatos polares dos ácidos graxos estão em ligações éster, os triacilgliceróis são moléculas apolares, hidrofóbicas e essencialmente insolúveis em água (NELSON e COX, 2014).

Historicamente, a biomassa tem sido largamente empregada como fonte de obtenção de diversos materiais, tais como fibras, polímeros e combustíveis, e este interesse pode ser atribuído ao seu caráter renovável e sua ampla disponibilidade. Neste contexto, os óleos e as gorduras animais e vegetais (triglicerídeos), in natura ou modificados, têm tido um papel importante em muitos segmentos. Alguns exemplos do potencial uso de óleos vegetais como 
auxiliares de processamento e/ou ativadores em composições de borracha são apresentados nos trabalhos de KURIAKOSE e VARGHESE (1999), SUAREZ et al. (2007), JAYEWARDHANA et al. (2009) e CHANDRASEKARA et al. (2011).

Assim sendo, nesta investigação, foi avaliada a utilização de óleos vegetais comestíveis - óleos de amendoim, coco e linhaça - e cera de abelha como potenciais ativadores em uma formulação elastomérica para a borracha de SBR. Tais produtos foram analisados como eventuais substitutos do ácido esteárico, um ácido graxo costumeiramente usado na indústria. Após a obtenção das diferentes misturas de SBR, os parâmetros reológicos, obtidos através de um analisador de processos de borracha (RPA), permitiram a determinação da cinética de vulcanização e a interpretação do efeito de cada substância.

\section{EXPERIMENTAL}

\subsection{Materiais}

Os diferentes reagentes e substâncias usados nesta investigação foram: o acelerador orgânico , N-terc-butil-benzotiazil-2-sulfenamida (TBBS), fabricante Nord Chemie Comércio de Produtos Químicos Ltda, usado como recebido; o ácido esteárico (origem animal), o enxofre e óxido de zinco em pó foram comprados junto à Silab Distribuidora Comercial Produtos Hospitalares Limitada, fabricante Isofar Indústria e Comércio Ltda, usados como recebidos.

O elastômero SBR (SB-1502 N) foi adquirido junto a Nitriflex S/A e é um copolímero de butadieno-estireno, polimerizado a frio, com baixo teor de estireno combinado $(22,0 \%-$ 25,0\%) e média viscosidade Mooney (MML1+4@100 $\mathrm{C}, 46-58)$. O SB-1502 N tem excelente resistência à tração, à abrasão, ao envelhecimento e ao calor; e, apresenta como principais aplicações: solados, adesivos e selantes, pneus e artefatos moldados em geral.

Os óleos vegetais comestíveis foram adquiridos no comércio local da cidade de Nova Friburgo. O óleo de amendoim (prensado a frio, não refinado, extra virgem), fabricante Pazze Indústria de Alimentos Ltda., foi usado como recebido. O óleo de coco, extra virgem,

\footnotetext{
Os ativadores são espécies químicas inorgânicas ou orgânicas que são usados para ativar ou extrair o potencial pleno dos aceleradores orgânicos. O óxido de zinco $(\mathrm{ZnO})$ é o ativador inorgânico mais amplamente usado (óxido de chumbo e óxido de magnésio são também empregados, porém em menor escala). Em muitas composições, hoje em dia, o ácido esteárico $\left(\mathrm{CH}_{3}\left(\mathrm{CH}_{2}\right)_{16} \mathrm{COOH}\right)$ é utilizado em conjunto com o $\mathrm{ZnO}$ (DICK, 2001; MONEYPENNY et al., 2004).

Nome comercial: Acelerador de vulcanização Santocure NS. É um acelerador de vulcanização com ação retardada, curto tempo de cura, possui notáveis características antiabrasivas e grande segurança no seu processamento. Muito utilizado em todos os tipos de borrachas e pneus. O produto é um excelente acelerador com mais ação retardada, com alta taxa de cura. Fonte: www.nordchemie.com.br<smiles>CC(C)(C)NSc1nc2ccccc2s1</smiles>
} 
fabricante Boa forma, e o óleo de linhaça dourada (extração a frio, extra virgem), fabricante Farinhas Integrais Cisbra Ltda, foram também usados como recebidos.

A cera de abelha, produzida por abelhas africanizadas (poli-híbridos do cruzamento da abelha africana Apis mellifera scutellata com a abelha europeia Apis mellifera caucásica), foi obtida mediante doação do Sítio Pé da Serra, localizado em São Pedro da Aldeia, Rio de Janeiro, RJ. De acordo com informações do apicultor, a cera foi derretida em uma panela, coada em peneira para retirada de impurezas e conformada em uma vasilha não tendo sido retirada a própolis. A cera foi usada como recebida, ou seja, não houve posterior tratamento físico-químico.

Nas Tabelas 1 e 2 encontram-se as informações físico-químicas e a composição dos diferentes óleos vegetais usados.

Tabela 1: Especificações técnicas dos óleos de amendoim, coco e linhaça características físico-químicas.

\begin{tabular}{lccc}
\hline \multicolumn{1}{c}{ Propriedade } & $\begin{array}{c}\text { Óleo de } \\
\text { amendoim }\end{array}$ & Óleo de coco & $\begin{array}{c}\text { Óleo de } \\
\text { linhaça }\end{array}$ \\
\hline Peso específico $\left(25^{\circ} \mathrm{C}, \mathrm{g} / \mathrm{cm}^{3}\right)$ & $0,911-0,914$ & $0,903-0,924$ & $0,924-0,930$ \\
\hline Índice de refração $\left(25^{\circ} \mathrm{C}\right)$ & $1,460-1,465$ & - & $1,477-1,482$ \\
\hline Índice de iodo $\left(\mathrm{g} \mathrm{I}_{2} / 100 \mathrm{~g}\right)$ & $80-106$ & $14-23$ & $170-203$ \\
\hline Índice de saponificação $(\mathrm{mg} \mathrm{KOH} \mathrm{/g)}$ & $187-196$ & $247-255$ & $188-196$ \\
\hline Matéria insaponificável $(\%)$ & $<1$ & & $0,1-2$ \\
\hline $\begin{array}{l}\text { Acidez (óleo refinado) }(\mathrm{g} \mathrm{de} \mathrm{ácido} \\
\text { oleico / } 100 \mathrm{~g})\end{array}$ & $<0,3$ & $<0,5$ & $<0,15$ \\
\hline Índice de peróxido $(\mathrm{meq} / \mathrm{kg})$ & $<10,0$ & - & - \\
\hline
\end{tabular}

Fonte: CAMPESTRE, 2015.

Tabela 2: Composição química dos óleos vegetais de amendoim, coco e linhaça.

\section{Óleo vegetal Composição média dos ácidos graxos (\%mol)}

\begin{tabular}{ccccccccccccc} 
& \multicolumn{1}{c}{ Saturados $^{1}$} & & \multicolumn{4}{c}{ Insaturados $^{2}$} \\
& $\mathrm{C}_{4}$ & $\mathrm{C}_{6}$ & $\mathrm{C}_{8}$ & $\mathrm{C}_{10}$ & $\mathrm{C}_{12}$ & $\mathrm{C}_{14}$ & $\mathrm{C}_{16}$ & $\mathrm{C}_{18}$ & $\mathrm{C}_{16}$ & ${ }^{*} \mathrm{C}_{18}$ & ${ }^{* *} \mathrm{C}_{18}$ & ${ }^{* * *} \mathrm{C}_{18}$ \\
\hline Amendoim & & & & & & $7-12$ & $2-6$ & & $30-60$ & $20-38$ & \\
\hline Coco & & $0-1$ & $5-7$ & $7-9$ & $40-50$ & $15-20$ & $9-12$ & $2-4$ & $0-1$ & $6-9$ & $0-1$ & \\
\hline Linhaça & & & & & & $4-7$ & $2-4$ & & $14-30$ & $14-25$ & $45-60$ \\
\hline
\end{tabular}

${ }^{1}$ Saturados: $\mathrm{C}_{4}=$ ácido butírico, P.F. $=-7,9^{\circ} \mathrm{C} ; \mathrm{C}_{6}=$ ácido caproico, P.F. $=-3^{\circ} \mathrm{C} ; \mathrm{C}_{8}=$ ácido caprílico, P.F. $=16-$ $17^{\circ} \mathrm{C} ; \mathrm{C}_{10}=$ ácido cáprico, P. F. $=31^{\circ} \mathrm{C} ; \mathrm{C}_{12}=$ ácido láurico, P.F. $=44-46^{\circ} \mathrm{C} ; \mathrm{C}_{14}=$ ácido mirístico, $\mathrm{P} . \mathrm{F}=54^{\circ} \mathrm{C}$; $\mathrm{C}_{16}=$ ácido palmítico, P.F. $=63^{\circ} \mathrm{C} ; \mathrm{C}_{18}=$ ácido esteárico, P.F. $=70^{\circ} \mathrm{C} .{ }^{2}$ Insaturados: $\mathrm{C}_{16}=$ ácido palmitoleico, P.F. $=32^{\circ} \mathrm{C} ;{ }^{*} \mathrm{C}_{18}=$ ácido oleico, P.F. $=4{ }^{\circ} \mathrm{C} ;{ }^{* *} \mathrm{C}_{18}=$ ácido linoleico, P.F. $=-5^{\circ} \mathrm{C} ;{ }^{* * *} \mathrm{C}_{18}=$ ácido linolênico, P.F. $=-11^{\circ} \mathrm{C}$. Fonte: CAMPESTRE, 2015. 
Na Tabela 3 é apresentada a formulação de SBR usada neste estudo. Ao todo foram avaliadas cinco misturas, onde cada mistura difere das demais pela substituição integral do ácido esteárico por uma quantidade equivalente de óleo vegetal ou cera de abelha.

Tabela 3: Formulação das diferentes composições de SBR.

\begin{tabular}{llc}
\hline & Ingrediente & Quantidade (phr) \\
\hline $\mathrm{SBR}$ & 100 \\
\hline $\mathrm{ZnO}$ & 5 \\
\hline $\mathrm{S}$ & & 1,8 \\
\hline 1. Ácido esteárico & 1,0 \\
2. Óleo de amendoim & 1,0 \\
3. Óleo de coco & 1,0 \\
4. Óleo de linhaça & 1,0 \\
5. Cera de abelha & 1,0 \\
\hline TBBS & 1,2 \\
\hline
\end{tabular}

*Os níveis de dosagem dos diversos constituintes são correntemente expressos em partes por 100 partes de polímero $(\mathrm{phr}=$ per hundred $)$.

Quanto à cera de abelha, a composição é bastante complexa, sendo constituída por uma mistura de substâncias de caráter lipídico e, portanto, bastante hidrofóbico. A composição da cera de abelha depende em parte das subespécies de Apis mellifera, da idade da cera, e das condições climáticas da sua produção. Esta variação ocorre principalmente na quantidade relativa dos diferentes componentes presentes do que propriamente na sua natureza. A mistura inclui hidrocarbonetos, ácidos graxos livres, monoésteres, diésteres, triésteres, hidroximonoésteres, hidroxipoliésteres, monoésteres de ácidos graxos, poliésteres de ácidos graxos e alguns componentes não identificados. Os ácidos graxos livres representam $12-15 \%$ da cera de abelha, sendo esta família de compostos constituídos por ácidos graxos de cadeia linear com um número par de átomos de carbono, na sua maioria por 20 a 36 átomos de carbono. O ácido graxo mais abundante na cera de abelha é o ácido tetracosanoico $^{\equiv}$, representando aproximadamente $6 \%$ da cera de abelha (BARROS et al., 2009).

\subsection{Processamento e análise reométrica}

As misturas foram conduzidas em linhas gerais de acordo com a norma ASTM D3182. Um misturador de rolos Berstoff, modelo $90-3 \mathrm{Wo} / 1335 / 69$, foi utilizado com uma razão de fricção de 1:1,25. Após a plastificação da borracha, óxido de zinco foi adicionado e, após a incorporação, os demais ingredientes foram adicionados em conjunto.

Para a obtenção das curvas de torque elástico (S') versus o tempo, as diferentes composições foram vulcanizadas utilizando um RPA 2000 Rubber Process Analyzer, Alpha

\footnotetext{
O ácido lignocérico ou ácido tetracosanoico é um ácido graxo saturado de cadeia linear com 24 átomos de carbono na fórmula, $\mathrm{C}_{23} \mathrm{H}_{47} \mathrm{COOH}$. $\mathrm{O}$ ácido lignocérico é um subproduto da produção de lignina. Ponto de fusão: $84^{\circ} \mathrm{C}$. Fonte: https://pt.wikipedia.org/wiki/acido_lignocerico.
} 
Technologies, com amplitude de oscilação de $\pm 1^{\circ}$. Três temperaturas $\left(150,160\right.$ e $\left.170{ }^{\circ} \mathrm{C}\right)$ foram selecionadas para o cálculo dos parâmetros cinéticos - constante de taxa para a reação $(k)$ e energia de ativação $\left(E_{a}\right)$. Em cada temperatura, três amostras de cada mistura foram analisadas.

\section{RESULTADOS E DISCUSSÃO}

\subsection{Dados reométricos}

Na Tabela 4 e nas Figuras 1 a 5, os dados reométricos, obtidos nas temperaturas de 150 a $170^{\circ} \mathrm{C}$, das diferentes composições de SBR são apresentados.

Após a câmara interna do reômetro de disco oscilatório ser selada, a amostra de borracha, sob o efeito da temperatura e pressão, flui continuamente até envolver o disco oscilatório e atinge-se um registro de torque mínimo $S_{l}^{\prime}$. Tal valor está diretamente relacionado à processabilidade das composições não vulcanizadas. Quanto maior o valor registrado de $\mathrm{S}_{\ell}$, mais difícil é o processamento da composição em questão, ou seja, mais viscosa é a mistura elastomérica. Indiretamente, em composições que não contêm cargas, $S^{\prime}{ }_{\ell}$ também pode fornecer valiosas informações sobre a velocidade da reação de vulcanização. Os valores elevados de $\mathrm{S}_{\ell}{ }_{\ell}$ significam que as reações entre os ingredientes da composição tiveram início em menor tempo. Desta forma, a viscosidade da mistura não pode ser reduzida o suficiente para que um registro baixo de $S^{\prime}{ }_{\ell}$ venha a ser obtido (MORTON, 1999).

Tabela 4: Dados reométricos das diferentes composições de SBR em função da temperatura de vulcanização.

\begin{tabular}{|c|c|c|c|c|c|}
\hline Composição & $S_{\ell}^{\prime}(d N . m)$ & $S^{\prime}{ }_{h}(d N . m)$ & $t_{s 1}(\min )$ & $t_{90}$ (min) & $\mathrm{T}\left({ }^{\circ} \mathrm{C}\right)$ \\
\hline \multirow[t]{3}{*}{ SBR/AcEst } & $1,7 \pm 0,1$ & $14,1 \pm 0,1$ & $17,6 \pm 0,2$ & $43,9 \pm 0,4$ & 150 \\
\hline & $1,5 \pm 0,1$ & $13,9 \pm 0,1$ & $8,9 \pm 0,1$ & $24,9 \pm 0,6$ & 160 \\
\hline & $1,3 \pm 0,1$ & $12,8 \pm 0,2$ & $4,2 \pm 0,2$ & $12,3 \pm 0,5$ & 170 \\
\hline \multirow[t]{3}{*}{ SBR/OAm } & $1,6 \pm 0,1$ & $12,5 \pm 0,1$ & $20,0 \pm 0,4$ & $48,4 \pm 0,1$ & 150 \\
\hline & $1,5 \pm 0,1$ & $13,0 \pm 0,1$ & $9,8 \pm 0,4$ & $29,6 \pm 0,6$ & 160 \\
\hline & $1,3 \pm 0,1$ & $11,7 \pm 0,1$ & $4,7 \pm 0,2$ & $14,1 \pm 0,4$ & 170 \\
\hline \multirow[t]{3}{*}{ SBR/OCoc } & $1,7 \pm 0,1$ & $13,4 \pm 0,2$ & $18,8 \pm 0,4$ & $45,7 \pm 0,3$ & 150 \\
\hline & $1,5 \pm 0,1$ & $13,0 \pm 0,2$ & $9,2 \pm 0,3$ & $24,9 \pm 0,4$ & 160 \\
\hline & $1,4 \pm 0,1$ & $12,1 \pm 0,1$ & $4,6 \pm 0,1$ & $12,6 \pm 0,1$ & 170 \\
\hline \multirow[t]{3}{*}{ SBR/OLin } & $1,7 \pm 0,1$ & $13,1 \pm 0,2$ & $19,5 \pm 0,4$ & $46,9 \pm 0,8$ & 150 \\
\hline & $1,5 \pm 0,1$ & $13,3 \pm 0,2$ & $9,4 \pm 0,2$ & $26,4 \pm 0,3$ & 160 \\
\hline & $1,4 \pm 0,1$ & $12,2 \pm 0,1$ & $4,6 \pm 0,1$ & $12,2 \pm 0,2$ & 170 \\
\hline \multirow[t]{3}{*}{ SBR/Cera } & $1,7 \pm 0,1$ & $12,7 \pm 0,1$ & $20,5 \pm 0,2$ & $49,1 \pm 0,2$ & 150 \\
\hline & $1,6 \pm 0,1$ & $13,0 \pm 0,7$ & $9,7 \pm 0,1$ & $27,8 \pm 1,3$ & 160 \\
\hline & $1,4 \pm 0,1$ & $12,1 \pm 0,2$ & $4,6 \pm 0,1$ & $14,0 \pm 0,5$ & 170 \\
\hline
\end{tabular}




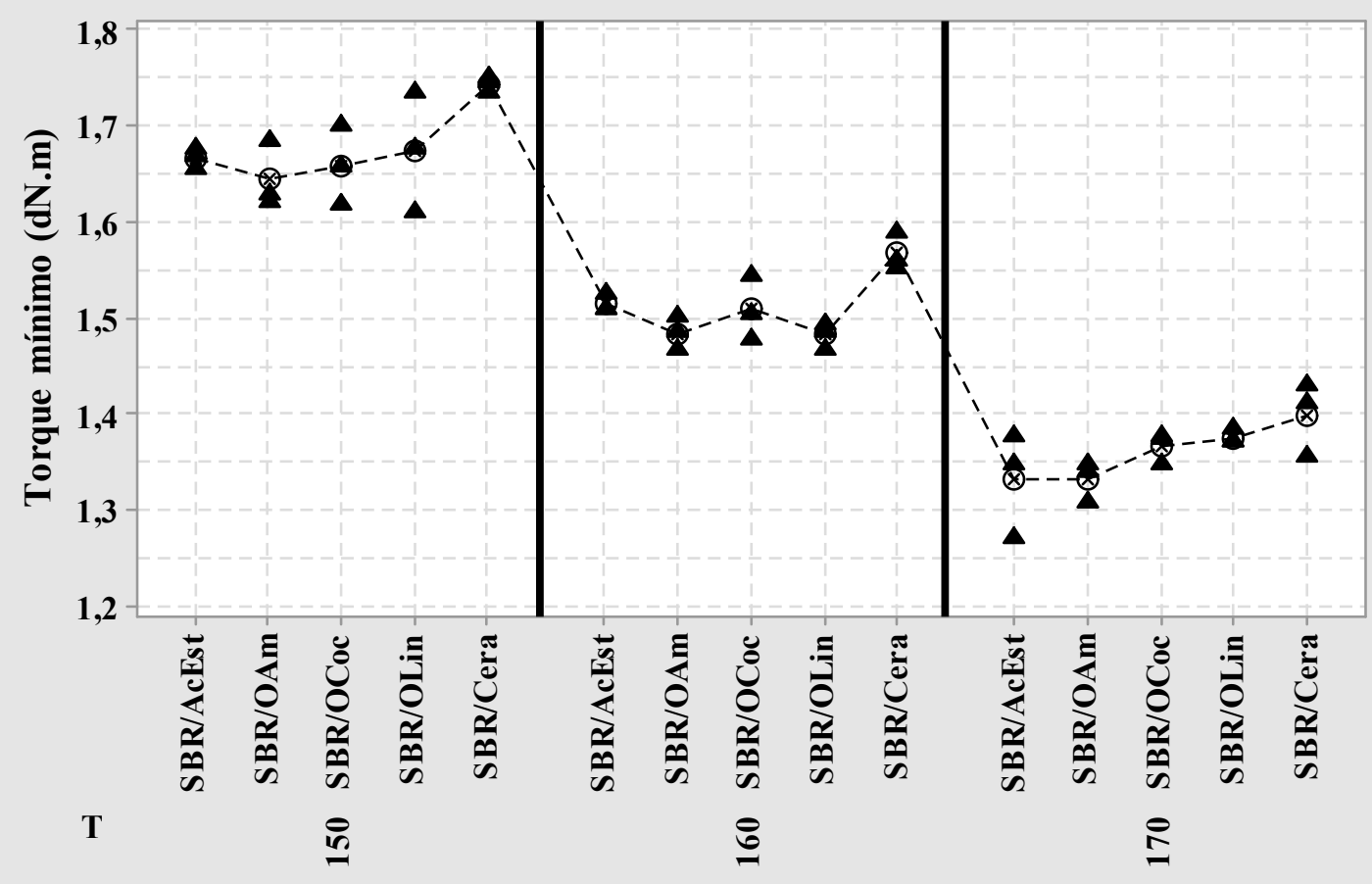

Figura 1: Variação do torque mínimo $\left(\mathrm{S}_{\ell}{ }_{\ell}\right)$ das diferentes composições de SBR com a temperatura.

Pôde ser observado através da Figura 1 e da Tabela 4 que a temperatura de vulcanização reduziu gradativamente os valores encontrados para o torque mínimo. Com uso do programa MINITAB ${ }^{\circledR}$ Тм 17.0, a metodologia ANOVA foi usada para o tratamento estatístico dos dados experimentais. A normalidade (teste de Shapiro-Wilk) e a igualdade de variância dos dados foram asseguradas e, para um nível de confiança de $95 \%$, não foram encontradas diferenças significativas entre as composições de SBR para uma mesma temperatura de vulcanização, ou seja, a substituição do ácido esteárico pelos óleos vegetais ou pela cera de abelha parece não ter influenciado o parâmetro reológico em questão.

O torque máximo $\left(\mathrm{S}_{h}{ }_{\mathrm{h}}\right)$ proporciona uma ideia da densidade de ligações cruzadas alcançada para uma composição em particular, após a vulcanização em dada temperatura. Pôde ser verificado através da Tabela 4 e da Figura 2 que os valores de $\mathrm{S}_{\mathrm{h}}$ apresentaram uma tendência à redução, à medida que a temperatura de vulcanização aumentou. Tal decréscimo é explicado pela produção de redes de ligações cruzadas com menor densidade de ligações polissulfídicas, além da formação de grupos sulfídicos intramoleculares e aumento na concentração de sulfeto de zinco (MORTON, 1999; DICK, 2001).

Além disso, foi também observado que todas as composições de SBR apresentaram a capacidade de vulcanizar. Contudo, as composições com os óleos vegetais ou com a cera de abelha não demonstraram uma reticulação tão efetiva quanto à composição padrão contendo ácido esteárico, ou seja, embora tenham permitido a vulcanização, não foram capazes de 
gerar uma rede de ligações cruzadas em igual magnitude àquela da composição convencional. A metodologia ANOVA foi novamente aplicada e, em um nível de confiança de 95\%, permitiu inferir que:

- Com a normalidade $(p=0,904)$ e a igualdade de variância $(p=0,245)$ dos dados foram asseguradas, em $150^{\circ} \mathrm{C}$, de acordo com o método de Holm-Sidak, comparações múltiplas foram efetuadas e demonstraram que as composições SBR/OCoc e $\mathrm{SBR} / \mathrm{OLin}$ e SBR/OAm e SBR/Cera foram equivalentes quanto ao parâmetro $\mathrm{S}_{\mathrm{h}}$; e,

- $\operatorname{Em} 160^{\circ} \mathrm{C}$ e $170^{\circ} \mathrm{C}$, novamente com a normalidade $(p=0,074 ; p=0,805)$ e a igualdade de variância $(p=0,438 ; p=0,626)$ dos dados garantida, de acordo com o método de Holm-Sidak, as composições de SBR com os óleos vegetais ou cera de abelha substancialmente se equipararam quanto efeito sobre o parâmetro $S{ }_{h}$, ainda que em $170^{\circ} \mathrm{C}$ a composição SBR/OAm seja estatisticamente diferente da composição SBR/OLin.

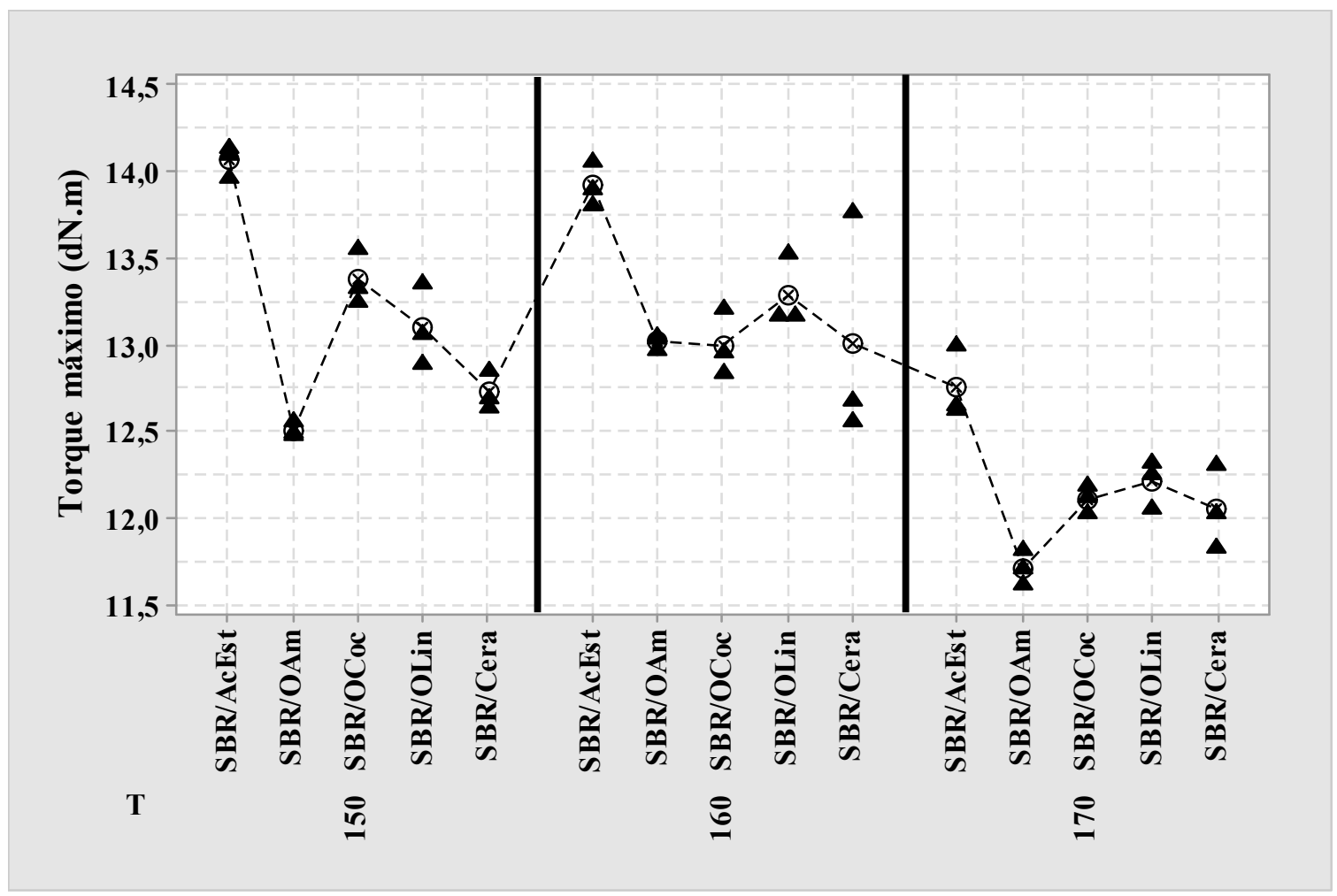

Figura 2: Variação do torque máximo $\left(\mathrm{S}_{h}{ }_{h}\right)$ das diferentes composições de SBR com a temperatura.

O tempo de pré-cura $\left(t_{s 1}\right)$ refere-se à vulcanização prematura, isto é, a reticulação da composição durante o estágio de processamento. Isto reduz as propriedades plásticas da composição interferindo na operação de moldagem do produto final. O tempo de pré-cura, então, geralmente define o tempo disponível para o processamento antes do início da vulcanização, em uma temperatura particular (MORTON, 1999; DICK, 2001). 
Através da Tabela 4 e da Figura 3, observou-se que um aumento na temperatura de vulcanização reduziu os tempos de pré-cura para todas as composições de SBR. De um modo geral, quase todas as reações químicas ocorrem mais rápido em temperaturas mais elevadas do que em temperaturas mais baixas (BRADY et al., 2003). Assim, a redução nos valores de $t_{s 1}$ refletiu tal premissa e a pré-cura tornou-se, em média, duas vezes mais rápida para um aumento de $10^{\circ} \mathrm{C}$ na temperatura.

A metodologia ANOVA, desta vez com o método de Dunnett de comparações múltiplas em relação ao grupo de controle SBR/AcEst e um nível de confiança de 95\%, revelou que:

- Para as temperaturas de $150^{\circ} \mathrm{C}$ (normalidade, $p=0,686$; igualdade de variância, $p=$ 0,937 ) e $170{ }^{\circ} \mathrm{C}$ (normalidade, $p=0,077$; igualdade de variância, $p=0,828$ ), a composição convencional de SBR contendo o ácido esteárico como ativador diferiu de forma significativa de todas as demais em relação ao tempo de pré-cura; e,

- $\operatorname{Em} 160^{\circ} \mathrm{C}$ (normalidade, $p=0,768$; igualdade de variância, $p=0,658$ ), foi observado que a composição $\mathrm{SBR} / \mathrm{AcEst}$ foi estatisticamente distinta apenas das composições $\mathrm{SBR} /$ Cera e SBR/OAm quanto ao parâmetro $\mathrm{t}_{\mathrm{s} 1}$.

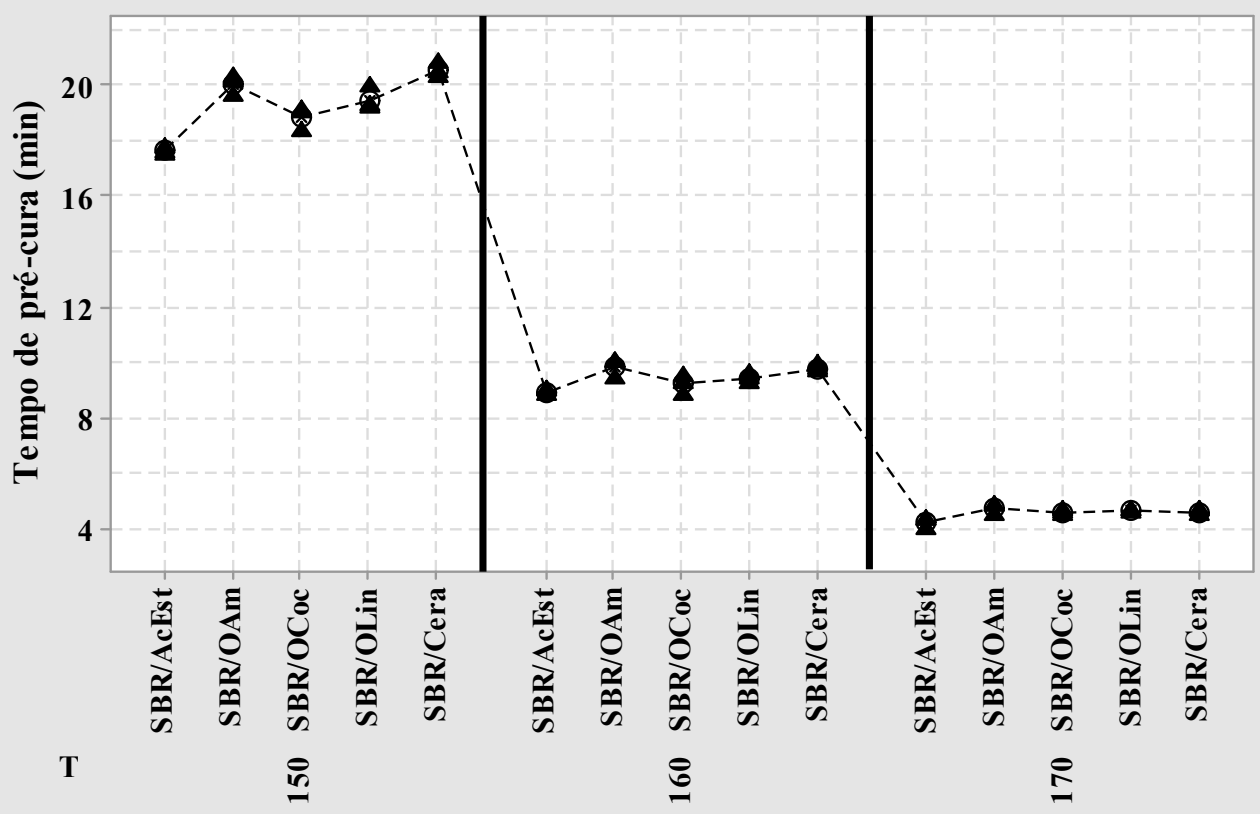

Figura 3: Variação do tempo de pré-cura $\left(t_{s 1}\right)$ das diferentes composições de SBR com a temperatura.

O tempo ótimo de cura ( $\left.t_{90}\right)$ é o tempo necessário durante a vulcanização para que uma dada quantidade de ligações cruzadas seja formada, conduzindo a um nível desejado de propriedades (MORTON, 1999; DICK, 2001). Através da Tabela 4 e da Figura 4, observou- 
se que o efeito do aumento da temperatura de vulcanização sobre os valores de $t_{90}$ foi similar ao observado na análise do $t_{\mathrm{s} 1} \mathrm{e}$, desta forma, seguiu o padrão já comentado. A metodologia ANOVA, com o método de Dunnett de comparações múltiplas em relação ao grupo de controle SBR/AcEst e um nível de confiança de 95\%, revelou que:

- $\quad$ Em $150^{\circ} \mathrm{C}$ (normalidade, $p=0,272$; igualdade de variância, $p=0,639$ ), a composição convencional de SBR contendo o ácido esteárico como ativador foi estatisticamente diferente de todas as demais, em relação ao tempo ótimo de vulcanização; e,

- Nas temperaturas de $160^{\circ} \mathrm{C}$ (normalidade, $p=0,783$; igualdade de variância, $p=$ 0,155 ) e $170^{\circ} \mathrm{C}$ (normalidade, $p=0,070$; igualdade de variância, $p=0,772$ ), foi observado que a composição SBR/AcEst diferiu apenas das composições SBR/Cera e SBR/OAm quanto ao parâmetro t90.

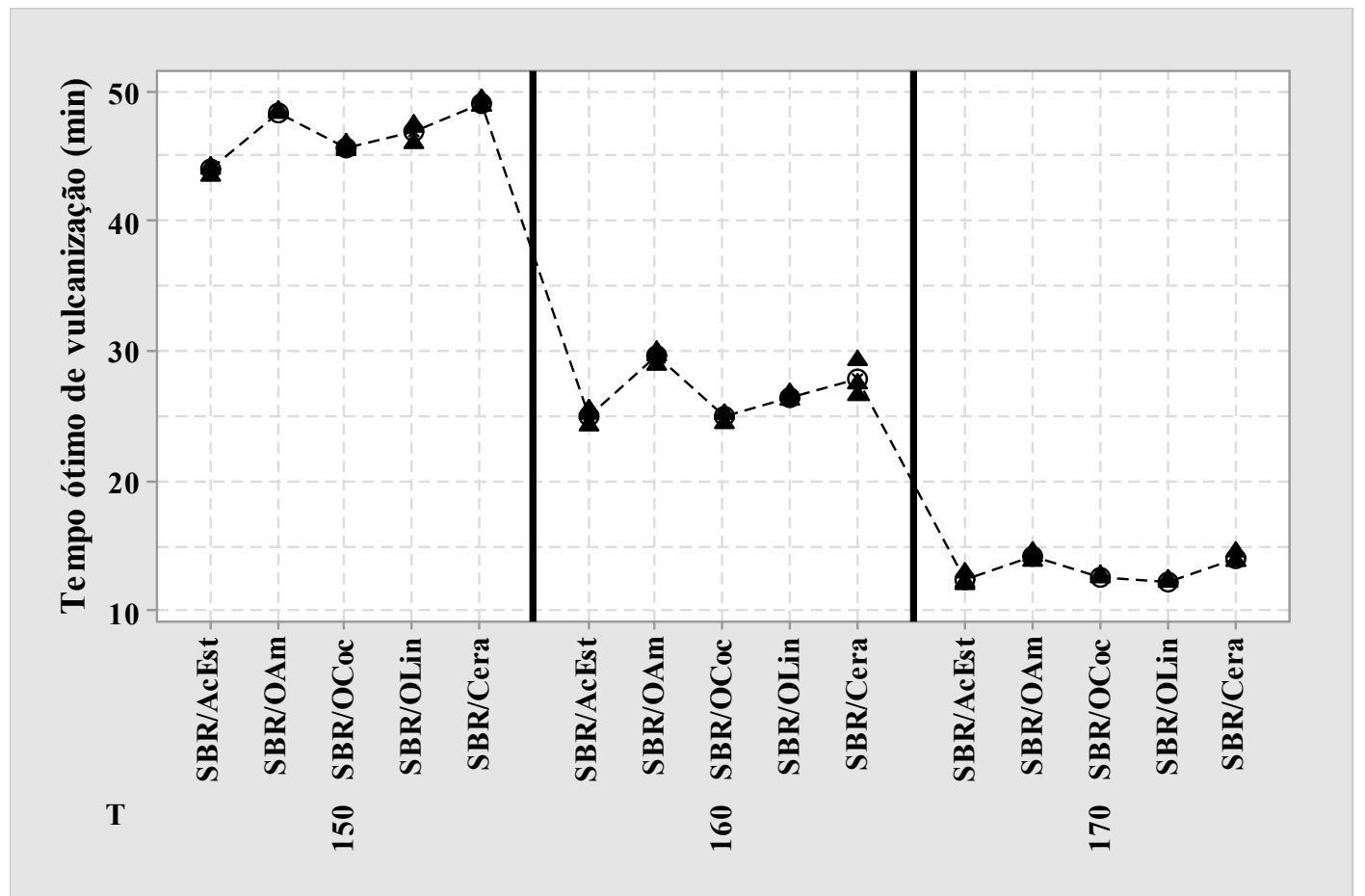

Figura 4: Variação do tempo ótimo de vulcanização $\left(t_{90}\right)$ das diferentes composições de SBR com a temperatura.

Através da análise dos dados reométricos, pôde ser visto que a vulcanização de SBR com ácido esteárico, óleos vegetais (amendoim, linhaça e coco) ou cera de abelha foi conduzida em linhas gerais da forma similar. Particularmente, a utilização das temperaturas de $160^{\circ} \mathrm{C}$ e $170^{\circ} \mathrm{C}$ com óleo de coco ou óleo de linhaça tornou equivalente o processo de vulcanização do SBR ao da mistura SBR/AcEst. A chave para a explicação das diferença nas redes de ligações cruzadas formadas pareceu residir na composição química complexa, bem como na presença de insaturações nos ácidos graxos presentes nos óleos vegetais e na cera de 
abelha. Assim, a fim de se avaliar melhor tal hipótese, o estudo da cinética de vulcanização foi conduzido.

\subsection{Cinética de vulcanização}

Medidas reométricas são baseadas no princípio de que a densidade de ligações cruzadas é proporcional à rigidez da borracha. Assim, o grau de conversão $(\alpha)$ em uma reação de cura pode ser determinada a partir das propriedades viscoelásticas medidas através de um reômetro (CHOUGH e CHANG, 1996; LOPEZ-MANCHADO et al., 2003; CHOI et al., 2005). O valor de $\alpha$ pode ser definido pela Equaçao 1:

$$
\alpha=\frac{S_{t}^{f}-S_{\ell}^{f}}{S_{h}^{f}-S_{\ell}^{f}}
$$

onde: $S{ }^{\prime}, S^{\prime}{ }_{t}$ e $S{ }_{h}$ correspondem ao torque elástico mínimo, torque elástico para um tempo de cura $t$ e torque elástico máximo, respectivamente.

De acordo com DENG-ISAYEV (1988), os parâmetros da cinética de vulcanização podem ser determinado através da Equação 2:

$$
\alpha=\frac{k \cdot\left(t-t_{s}\right)^{n}}{1+k \cdot\left(t-t_{s}\right)^{n}}
$$

onde: $k$ é a constante de velocidade, normalmente correlacionada com a temperatura pela equação de Arrhenius; n é a ordem de reação; e, $t_{s}$ é o tempo de pré-cura, o qual pode ser definido como o tempo decorrido entre o início do teste e o começo do aumento do torque a partir do S' $\ell$ em função da reticulação (ARRILLAGA et al., 2007).

A partir das curvas reométricas, os graus de conversão alcançados durante a vulcanização das composições de SBR foram obtidos usando-se a Equação 1. Posteriormente, a Equação 2 foi usada para a determinação dos parâmetros cinéticos $k$ e $n$ usando-se a metodologia de regressão não-linear (método de Gauss-Newton com um máximo de 200 interações e limite de tolerância de $10^{-6}$ ). Finalmente, de posse dos valores de $k$ para cada temperatura investigada, os valores de $E_{a}$ foram estimados.

Na Figura 5 é apresentada a variação da constante de velocidade $k$ em relação à temperatura de vulcanização para as diferentes composições de SBR. De acordo com a equação de Arrhenius, o valor da constante de velocidade $k$ aumenta com a temperatura (RUSSEL, 1994). Pôde ser observado que a constante de velocidade aumentou de um fator de aproximadamente 2 ou 3 para cada aumento de $10^{\circ} \mathrm{C}$ na temperatura de vulcanização de todas as composições, embora a quantidade de fato do aumento tenha sido diferente de uma composição para outra. 


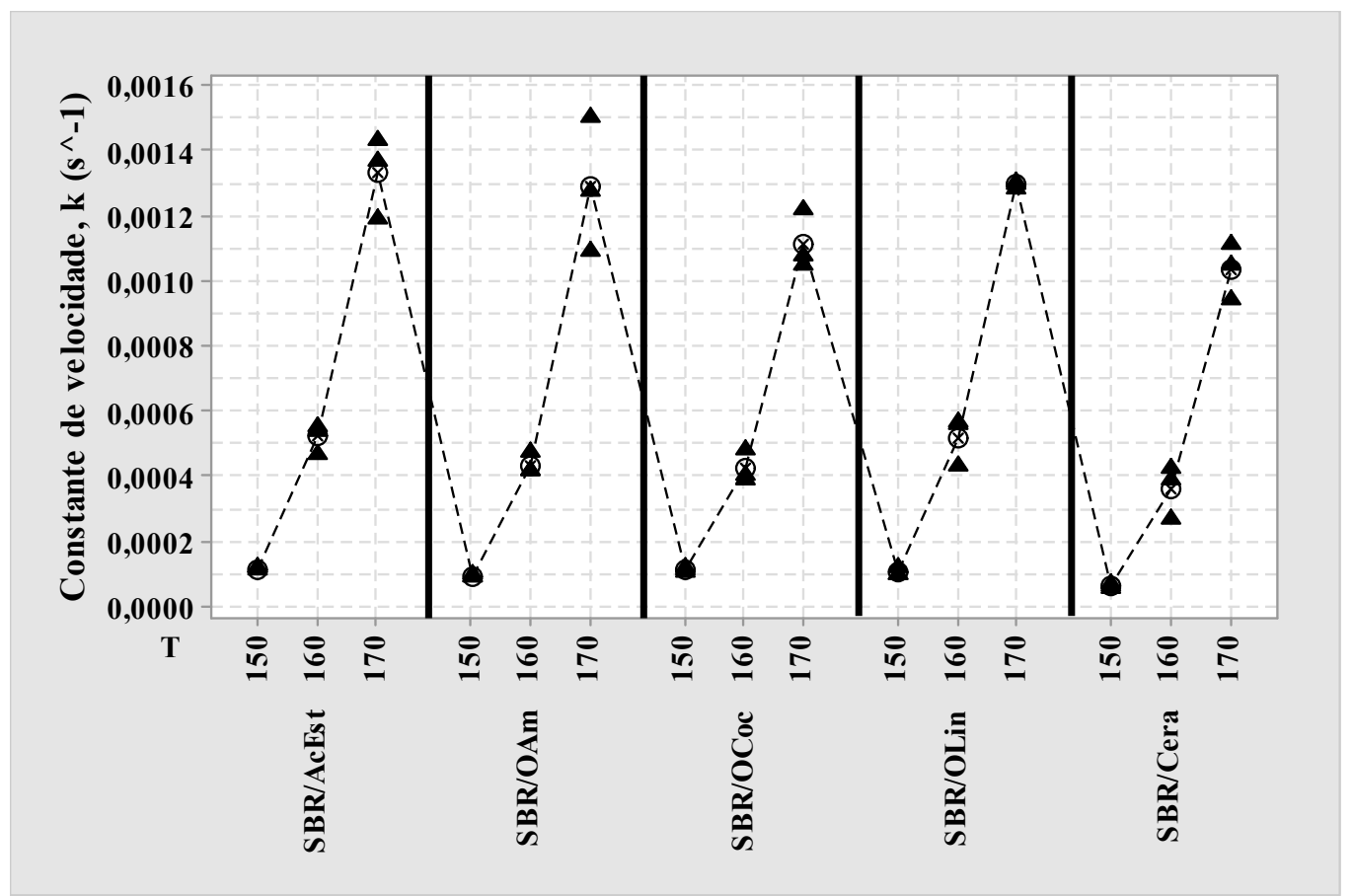

Figura 5: Variação da constante de velocidade $k$ em função da temperatura de vulcanização para as diferentes composições de SBR.

Para averiguar o efeito conjunto da temperatura e do tipo de ativador, o procedimento de ANOVA fatorial foi usado considerando-se dois fatores independentes (temperatura, com três níveis; e, tipo de ativador, com cinco níveis) influenciando a constante de velocidade $k$. Os testes de normalidade e igualdade de variâncias foram falhos, pois em ambos $p<0,050$ foi encontrado. Desta forma, o teste de comparações múltiplas de Holm-Sidak foi aplicado e demonstrou que:

- A temperatura foi o fator independente mais expressivo $(F(2,30)=805,7, p=0,000)$ sobre a constante de velocidade $k$. Para todas as composições de SBR investigadas foram encontradas diferenças estatisticamente significativas em $k$ especificamente com relação à temperatura;

- Por sua vez, o tipo de aditivo como fator independente apresentou uma influência bem menor $(F(4,30)=7,23, p=0,000)$ sobre o parâmetro $k$. De um modo geral, apenas os pares SBR/Cera - SBR/AcEst, SBR/Cera - SBR/OLin e SBR/Cera SBR/OAm foram estatisticamente diferentes em um nível de confiança de $95 \%$; e,

- A possível influência conjunta (efeito combinado) dos fatores temperatura e tipo de aditivo não foi considerada expressiva $(F(8,30)=1,84, p=0,108)$. Ainda assim, considerando-se a análise conjunta dos fatores: (i) para uma mesma temperatura, apenas em $170^{\circ} \mathrm{C}$ foram encontradas diferenças estatisticamente significativas entre os pares SBR/Cera - SBR/AcEst, SBR/Cera - SBR/OLin, SBR/Cera - SBR/OAm e $\mathrm{SBR} / \mathrm{OCoc}$ - SBR/OLin; (i) para um mesmo tipo de aditivo, em todos os casos foi verificado que os valores de $k$ variavam significativamente em função da temperatura. 
Na Figura 6 são dispostas as ordens de reação $(n)$ encontradas para as diferentes composições de SBR em função da temperatura e do tipo de aditivo selecionado. Mais uma vez o procedimento de ANOVA fatorial foi usado com duas variáveis independentes (temperatura, com três níveis; e, tipo de ativador, com cinco níveis) influenciando na ordem da reação de vulcanização.

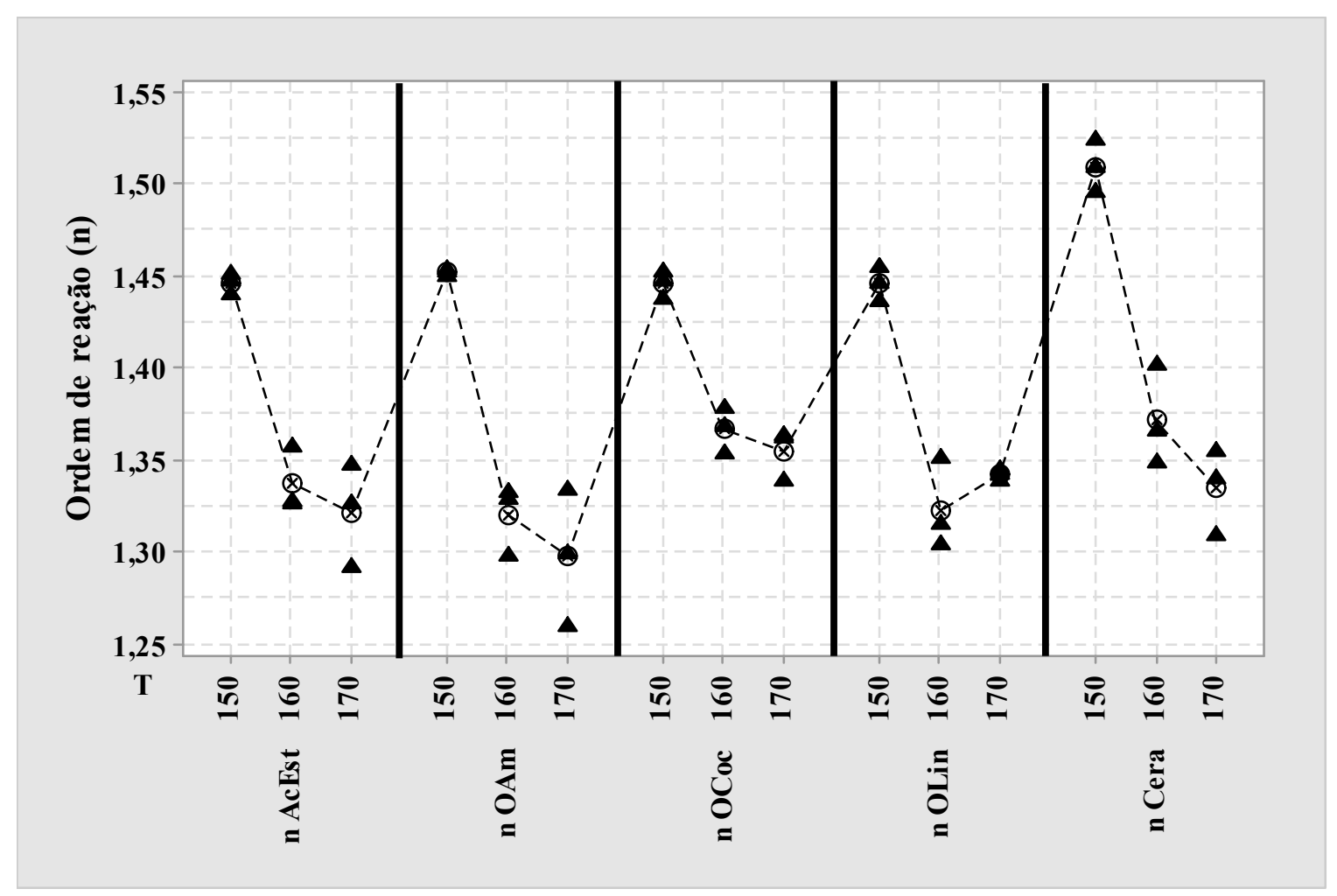

Figura 6: Variação da ordem de reação com a temperatura para a vulcanização das diferentes composições de SBR.

O teste de normalidade de Shapiro-Wilk $(p=0,891)$ e o teste da igualdade de variância entre os dados $(p=0,141)$ asseguraram a coerência da abordagem estatística e o método de Holm-Sidak para comparações múltiplas foi aplicado. Para um nível de confiança de $95 \%$, pôde ser observado que:

- A temperatura foi a variável independente que exerceu a maior influência sobre a ordem de reação de vulcanização das composições de $\operatorname{SBR}(F(2,30)=208,28, p<$ $0,001)$, onde os valores de $n$ foram estatisticamente equivalentes apenas o par $160^{\circ} \mathrm{C}$ $170^{\circ} \mathrm{C}$;

- O fator independente tipo de aditivo (ácido esteárico, óleo de amendoim, óleo de coco, óleo de linhaça ou cera) exerceu também influência sobre a ordem de reação, embora tenha sido menos significativo que a temperatura $(F(4,30)=9,215, p<0,001)$. Os 
valores encontrados para as composições de SBR/Cera foram estatisticamente diferentes daqueles determinados para as composições SBR/AcEst, SBR/OAm e $\mathrm{SBR} / \mathrm{OLin}$; além disso, houve também diferença expressiva para $n$ entre SBR/OCoc e SBR/Oam; e,

- A influência conjunta (efeito combinado) das variáveis temperatura e tipo de aditivo sobre a ordem de reação $n$ das composições de SBR foi o fator menos relevante $(F(8,30)=2,98, \mathrm{p}=0,014))$. Em relação aos aditivos: (i) em $150^{\circ} \mathrm{C}$, a composição $\mathrm{SBR} /$ Cera diferiu de todas as demais composições; (ii) em $160^{\circ} \mathrm{C}$, diferenças foram encontradas entre os pares SBR/Cera - SBR/OAm, SBR/Cera - SBR/OLin e $\mathrm{SBR} / \mathrm{OCoc}$ - SBR/OAm; e, (iii) em $170^{\circ} \mathrm{C}$, apenas o par SBR/OCoc - SBR/OAm mostrou diferença significativa para $n$. Em relação à uma temperatura em particular: (i) o ácido esteárico ou qualquer um dos óleos vegetais foram estatisticamente equivalentes quanto à influência individual sobre $n$ nas temperaturas de $160^{\circ} \mathrm{C}$ e $170^{\circ} \mathrm{C}$; e, (ii) a composição de SBR com cera de abelha apresentou dados de $n$ estatisticamente diferentes para quaisquer das temperaturas investigadas.

A energia de ativação $\left(E_{a}\right)$ pode ser entendida como a energia mínima que as moléculas reagentes, que colidem, devem ter para a formação dos produtos. A teoria do estado de transição focaliza a maneira pela qual os átomos se rearrajam e a sequência das variações de energia potencial que ocorrem durante o processo elementar. De acordo com esta teoria, quando as partículas colidem com energia igual ou maior do que a energia de ativação, das colisões resulta um complexo ativado, o qual é um agregado instável e temporário de átomos, fracamente ligados. O complexo ativado pode, então, se decompor nos reagentes ou nos produtos (RUSSEL, 1994).

Na Figura 7 são apresentados os valores de energia de ativação para as diferentes composições de SBR. A análise estatística dos dados experimentais, para um nível de confiança de $95 \%$ e com o grupo de controle SBR/AcEst, revelou que apenas a composição $\mathrm{SBR} /$ Cera exibiu valor de $E_{a}$ significativamente diferente, ou seja, as composições que usaram óleo vegetal (óleo de amendoim, linhaça ou coco) como ativador vulcanizaram em um patamar de energia similar ao da composição convencional com ácido esteárico.

O processo de vulcanização está ilustrado na Figura 8 e pode ser resumidamente descrito da seguinte maneira (JOSEPH et al., 2015):

i. Primeiro, um complexo ativo do acelerador é formado através de uma interação preliminar entre o acelerador e o ativador, na presença de zinco solúvel. Esse complexo pode reagir com o enxofre molecular, mediante a abertura do anel de $\mathrm{S}_{8}$, para formar um agente sulfurante.

ii. Em etapa subsequente, o agente sulfurante pode reagir com as cadeias de borracha para formar um precursor de ligações cruzadas. A evolução do precursor leva ao desenvolvimento de ligações cruzadas polissulfídicas.

iii. Por fim, a diminuição da eficiência na formação de ligações cruzadas pode ocorrer devido a reações laterais, como decomposição ou dessulfurização dos precursores. 
Devido a estas reações laterais, a formação de sulfetos cíclicos, dienos conjugados, trienos, ZnS, e grupos monossulfídicos pendentes pode ser observada. Estas espécies não são capazes de contribuir para a geração de ligações cruzadas.

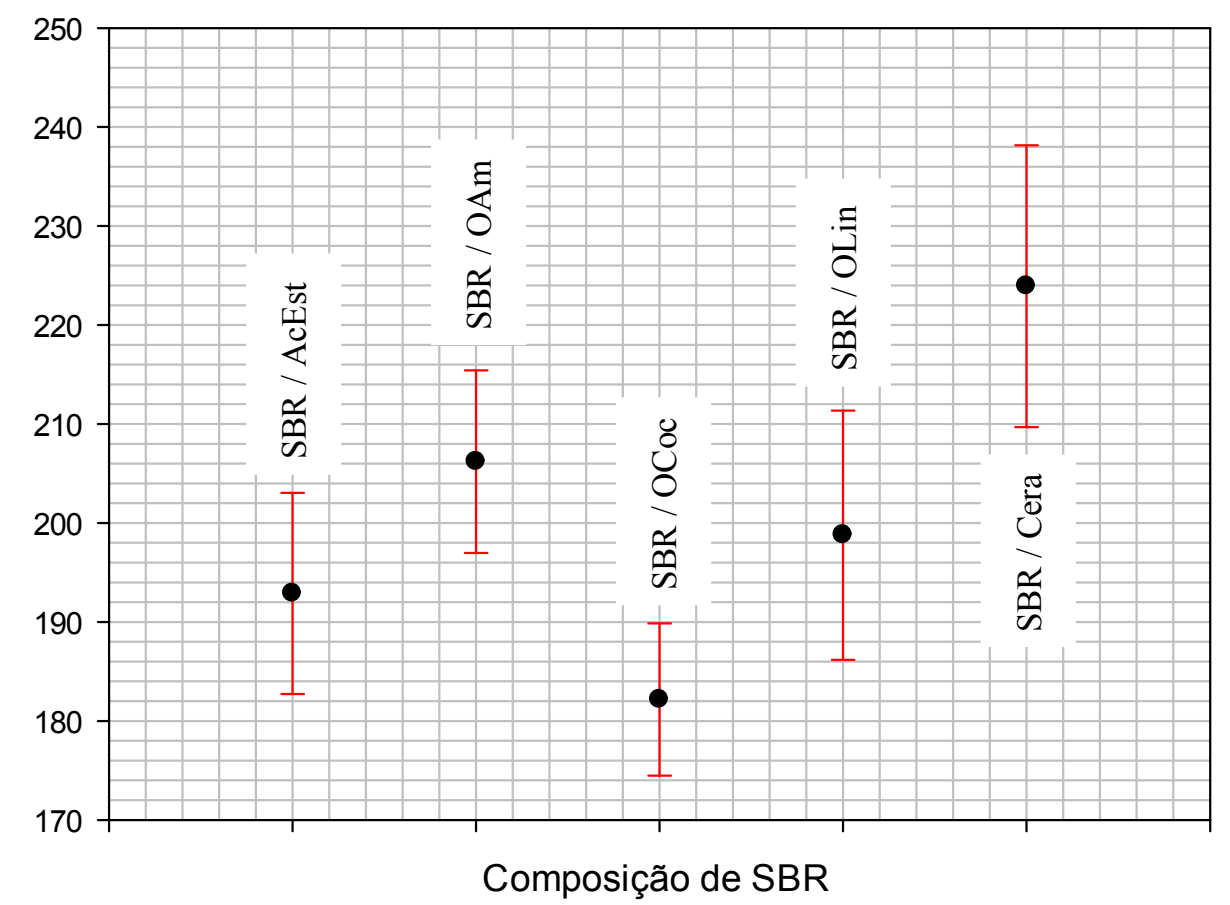

Figura 7: Variação da energia de ativação para as diferentes composições de SBR.

Estudos mostraram que a atividade, a concentração do complexo zinco-acelerador e a temperatura são as principais variáveis de controle para as possíveis reações laterais citadas. A rede de ligações cruzadas inicial sofre maturação, ou seja, é consolidada, e durante esse processo ocorre a dessulfurização (diminuição do tamanho das ligações cruzadas, eventualmente levando a ligações monossulfídicas) e/ou a decomposição das ligações cruzadas polissulfídicas (JOSEPH et al., 2015). Desta forma, os parâmetros reométricos que foram encontrados experimentalmente e discutidos através da metodologia estatística ANOVA permitem inferir que:

- Embora não tenha apresentado efeitos adversos quanto a pré-cura ou torque mínimo, a composição SBR/Cera não produziu um vulcanizado com uma rede de ligações cruzadas eficaz. Os baixos valores de $\mathrm{S}$ ' ${ }_{\mathrm{h}}$ quando comparados aos da composição SBR/AcEst, particularmente em $160^{\circ} \mathrm{C}$, aliados aos maiores valores de ordem de reação, $n$, e energia de ativação, $E_{a}$, refletiram a dificuldade da cera de abelha atuar como um ativador efetivo na formulação do SBR. Provavelmente, a composição química extremamente complexa da cera, conforme descrita por BARROS et al. (2009), permitiu a ocorrência de uma série de reações em paralelo, as quais certamente foram indesejáveis ao esquema descrito na Figura 8;

- Os óleos vegetais demonstraram, em linhas gerais, uma equivalência no papel de possíveis ativadores quando os dados experimentais foram comparados aos da 
composição SBR/AcEst. Além disso, os valores de $n$ e $E_{a}$ também apresentaram considerável similaridade. No entanto, se uma ordem crescente de eficiência for sugerida teríamos: óleo de amendoim $<$ óleo de linhaça $<$ óleo de coco.

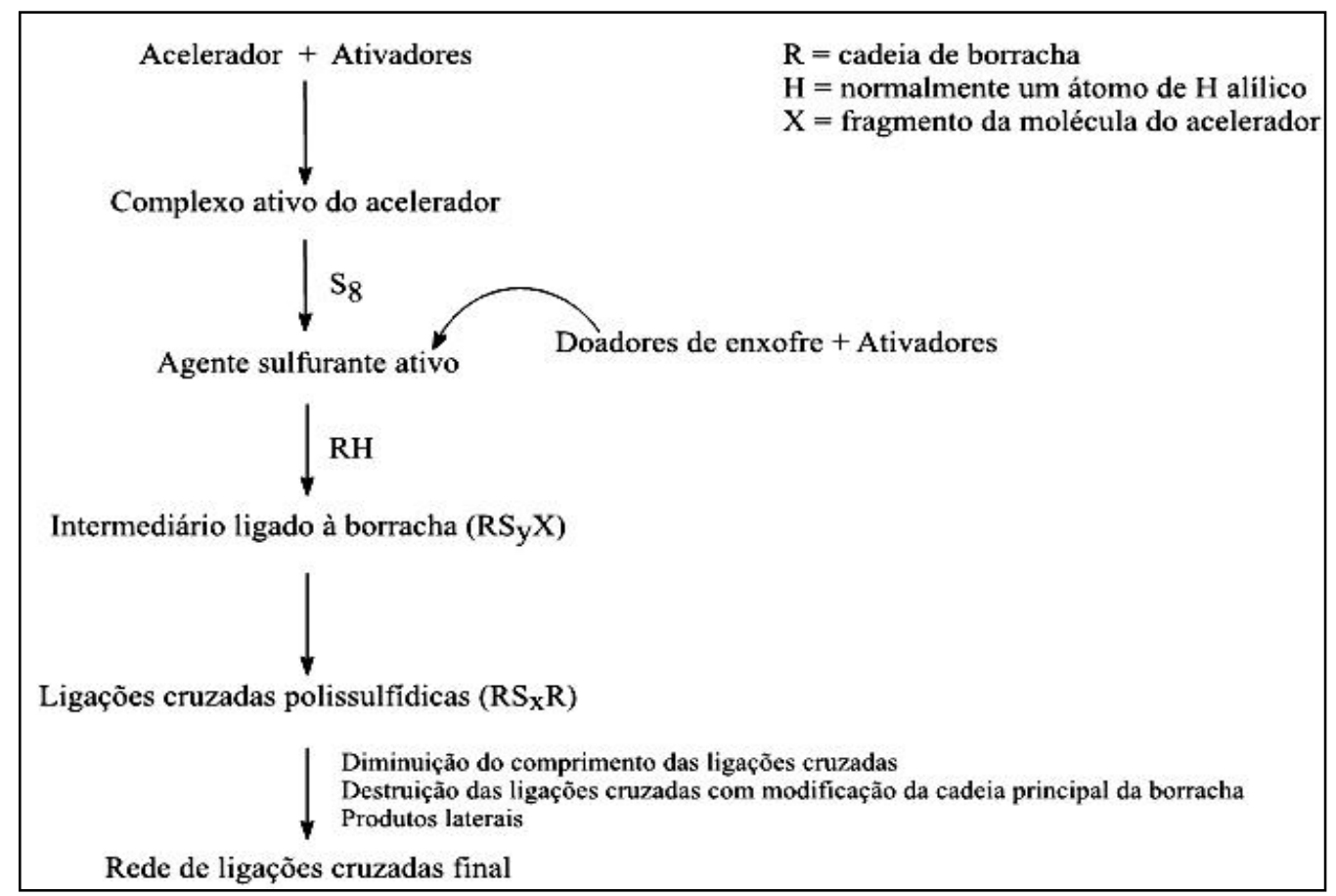

Figura 8: Esquema simplificado do mecanismo de vulcanização de elastômeros usando o enxofre. Fonte: DA COSTA et al., 2003.

O ácido esteárico (ácido octadecanóico) é um ácido graxo saturado com 18 carbonos, de fórmula química $\mathrm{CH}_{3}\left(\mathrm{CH}_{2}\right)_{16} \mathrm{COOH}$. Por sua vez, o óleo de coco é constituído majoritariamente, 40 a 50\%, por ácido láurico (ácido dodecanóico), $\mathrm{CH}_{3}\left(\mathrm{CH}_{2}\right){ }_{10} \mathrm{COOH}$; e, 15 a $20 \%$, por ácido mirístico (ácido tetradecanóico), $\mathrm{CH}_{3}\left(\mathrm{CH}_{2}\right)_{12} \mathrm{COOH}$. Tais ácidos graxos são também saturados e, desta maneira, é possível que o óleo de coco possa ter proporcionado um mecanismo de vulcanização bastante similar ao obtido quando se usa como ativador o ácido esteárico.

O óleo de amendoim possui como principais constituintes os ácidos oleico (ácido cis9-octadecenóico) e linoleico (ácido cis, cis-9,12-octadecadienoico), os quais são ácidos graxos insaturados com 18 carbonos na sua estrutura e dupla ligação entre os carbonos 9 e 10 ou entre os carbonos 9 e 10 e 12 e 13, respectivamente. O óleo de linhaça, por sua vez, tem como principal componente o ácido linolênico (ácido cis, cis, cis-9,12,15-octadecatrienóico), o qual é um ácido graxo insaturado de 18 carbonos e três duplas ligações nos carbonos 9,12 e 15 .

Na Figura 9 são apresentadas as diferentes estruturas para o ésteres inorgânicos de zinco formados pela interação do $\mathrm{ZnO}$ com os diferentes tipos de ácidos graxos. 


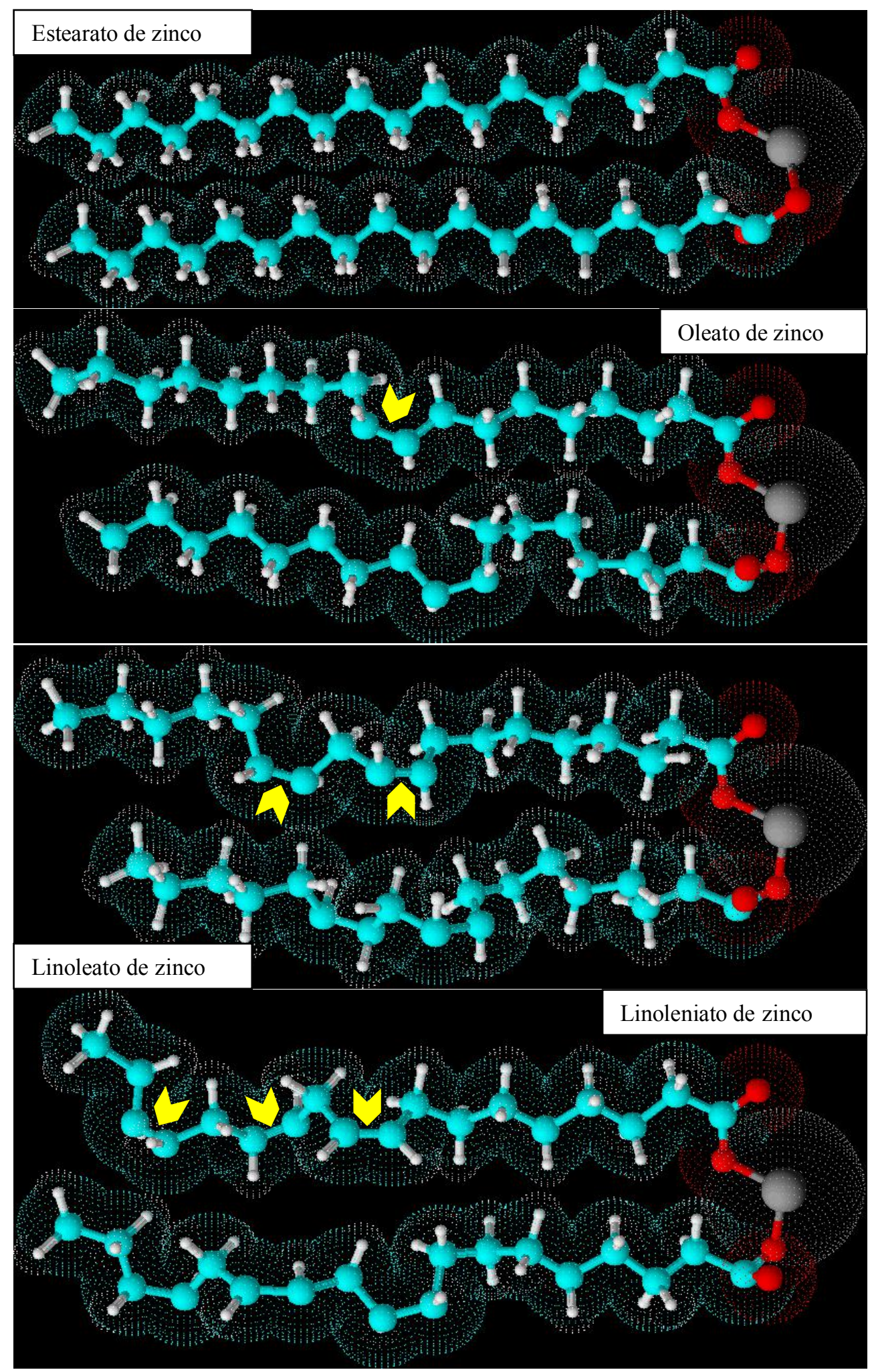

Figura 9: Diferentes estruturas para o esterato de zinco formado, conforme o tipo de ácido graxo usado como ativador. 
Para os ácidos graxos insaturados são indicadas as ligações duplas, as quais são possíveis sítios reativos para reações laterais. A dupla ligação presente na cadeia dos ácidos graxos pode ser oxidada, resultando em produtos cuja natureza depende do agente oxidante empregado e das condições de reação. Além disso, uma reação característica dos compostos com ligação dupla carbono-carbono é a adição, pois a ligação $\pi$ é particularmente suscetível aos reagentes que procuram elétrons (reagentes eletrofílicos) (SOLOMONS e FRYHLE, 2005).

A dupla ligação presente na cadeia dos ácidos graxos pode ser oxidada, resultando em produtos cuja natureza depende do agente oxidante empregado e das condições de reação. Além disso, uma reação característica dos compostos com ligação dupla carbono-carbono é a adição, pois a ligação $\pi$ é particularmente suscetível aos reagentes que procuram elétrons (reagentes eletrofílicos) (SOLOMONS e FRYHLE, 2005). Consequentemente, o óleo de amendoim, por sua composição química rica em dois ácidos graxos insaturados, parece ser capaz propiciar mais reações laterais indesejáveis ao curso normal da reação de vulcanização do que o óleo de linhaça. Tal hipótese se sustenta nos baixos valores de torque máximo ( $\mathrm{S}_{\mathrm{h}}{ }^{\text {) }}$ alcançados nas composições de SBR/OAm, particularmente em $160^{\circ} \mathrm{C}$.

\section{CONCLUSÕES}

A utilização de óleos vegetais - amendoim, coco e linhaça - e cera de abelha foram substâncias avaliadas como possíveis ativadores em composições de SBR em substituição ao ácido esteárico. Pelos dados experimentais obtidos, cinética de vulcanização e a análise estatística, pôde-se concluir que:

- Todas as substâncias avaliadas demonstraram alguma atividade com relação à vulcanização da borracha de estireno-butadieno, pois os parâmetros reológicos revelaram a formação de uma rede de ligações cruzadas. A cera de abelha por sua composição química complexa e contaminação com própolis não parece ser útil para o propósito delineado nesta investigação, embora outras funções para a mesma não possam ser descartadas e mereçam pesquisas posteriores;

Os óleos vegetais apresentam desempenho influenciado diretamente pela composição química, ou seja, pelas proporções relativas e tipos de ácidos graxos presentes. O óleo de coco, cuja composição revela teores expressivos de ácidos graxos saturados - ácido láurico e ácido mirístico - foi aquele que mais mostrou-se promissor para uma eventual aplicação como ativador do sistema de vulcanização escolhido neste estudo.

\section{AGRADECIMENTOS}

Os autores agradecem aos órgãos de fomento CNPq, CAPES e FAPERJ; ao IMA / UFRJ e ao INT pelo processamento e análise reométrica das diferentes misturas; e ao Programa Bolsista Produtividade da UNESA/2016. 


\section{REFERÊNCIAS}

ARRILlAGA, A., ZALDUA, A. M., ATXURRA, R. M., FARID, A. S. Techniques used for determining cure kinetics of rubber compound. European Polymer Journal, 43(11), 4783-4799, 2007.

BARROS, A. I. R. N., NUNES, F. H. F. M., DA COSTA, M. M. F. Manual de boas práticas na produção de cera de abelha: Princípios gerais. FNAP - Federação Nacional dos Apicultores de Portugal, Bragança, Portugal, 2009.

CAMPESTRE. Campestre Indústria e Comércio de Óleos Vegetais Ltda. Disponível em: < http://www.campestre.com.br >. Acesso em: 05 jan. de 2017.

CHANDRASEKARA, G., MAHANAMA, M. K., EDIRISINGHE, D. G., KARUNANAYAKE, L. Epoxidized vegetable oils as processing aids and activators in carbono-black filled natural rubber compounds. Journal of the National Science Foundation of Sri Lanka, 39(3), 243 - 250, 2011.

CHOI, D., KADER, M. A., CHO, B. H., HUH, Y., NAH, C. Vulcanization kinetics of nitrile rubber/layered clay nanocomposites. Journal of Applied Polymer Science, 98(4), 1688-1696, 2005.

CHOUGH, S. H., CHANG, D. H. Kinetics of sulfur vulcanization of NR, BR, SBR, and their blends using a rheometer and DSC. Journal of Applied Polymer Science, vol. 61(3), 449-454, 1996.

DA COSTA, H. M., VISCONTE, L. L. Y., NUNES, R. C. R., FURTADO, C. R. G. Aspectos Históricos da Vulcanização. Polímeros: Ciência e Tecnologia, v. 13( 2), p. 125-129, 2003.

DENG J. S., ISAYEV, A. I. No isothermal vulcanization of rubber compounds. Rubber Chemistry and Technology, 61(2), 340-361, 1988.

DICK, J. S. Rubber compounding: Introduction, definitions, and available resources, In: Rubber Technology, compounding and testing for performance, cap. 1, Dick, J. S. (ed.), Hanser Publishers, Munich, 2001.

JAYEWARDHANA, W. G. D., PERERA, G. M., EDIRISINGHE, D. G., KARUNANAYAKE, L. Study on natural oils as alternative processing aids and activators in carbon black filled natural rubber. Journal of the National Science Foundation of Sri Lanka, 37(3), 187 - 193, 2009.

JOSEPH, A. M., GEORGE, B., MADHUSOODANAN, K. N., ALEX, R. Current status of sulphur vulcanization and devulcanization chemistry: process of vulcanization. Rubber Science, v. 28(1), p. 82-121, 2015.

KURIAKOSE, A. P., VARGHESE, M. The compounding of nitrile and polychloroprene rubbers with rice bran oil. Iranian Polymer Journal, 8(4), 247 - 255, 1999.

LOPEZ-MANCHADO, M. A., ARROYO, M., HERRERO, B., BIAGIOTTI, J. Vulcanization kinetics of natural rubber-organoclay nanocomposites. Journal of Applied Polymer Science, 89(1), 1-15, 2003.

MARINHO, J. R. D. Propriedades físicas, mecânicas e estruturais. In: Macromoléculas e Polímeros. Capítulo 2, 1 aEdição, Editora Manole Ltda., São Paulo, 2005.

MONEYPENNY, H. G., MENTING, K. H., GRAGG, F. M. General Compounding, in: Rubber compounding. Chemistry and Applications, cap.8, Rodgers, B. (ed.), 1 $\frac{\mathrm{ed}}{\text {, }}$ Marcel Dekker, Inc., USA, 2004. 
NELSON, D. L., COX, M. M. Lipídeos, In: Princípios de Bioquímica de Lehninger, cap. 10, ARTMED Editora Ltda., 6를 São Paulo, SP, 2014.

RUSSEL, J. B. Cinética Química, In: Química Geral, cap. 13, Makron Books, Pearson

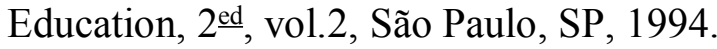

SOLOMONS, T. W. G., FRYHLE, C. B. Alcenos e Alcinos II: Reações de Adição, In: Química Orgânica, cap.8, vol.1, 8ª̉Edição, LTC Editora, São Paulo, SP, 2005.

SUAREZ, P. A. Z., MENEGHETTI, S. M. P, MENEGHETTI, M. R., WOLF, C. R. Transformação de triglicerídeos em combustíveis, materiais poliméricos e insumos químicos: algumas aplicações da catálise na oleoquímica. Química Nova, v. 30(3), p. 667-676, 2007. 